\title{
THE DEVELOPMENTAL STRATEGIES OF ENDOPARASITOID WASPS VARY WITH HOST FEEDING ECOLOGY
}

\author{
Jeffrey A. Harvey ${ }^{1,2}$ And Michael R. Strand ${ }^{1,3}$ \\ Department of Entomology, University of Wisconsin, Madison, Wisconsin 53706 USA
}

\begin{abstract}
Among the most important trade-offs in life history evolution is whether to grow larger at the cost of longer development time, or to develop more rapidly at the cost of reduced size. For insect herbivores, resolution of this trade-off is thought to be strongly influenced by feeding ecology and mortality risks. In contrast, how these factors might affect the developmental strategies of third trophic level organisms, like parasitoid wasps, is less understood. To address this question, we compared the development of larval endoparasitoids in the families Ichneumonidae and Braconidae that parasitize larval stage herbivores in the order Lepidoptera. The campoplegine ichneumonid Venturia canescens parasitized concealed hosts and exhibited a developmental strategy that favored progeny size over development time. In contrast, the closely related ichneumonid Campoletis sonorensis parasitized exposed hosts and exhibited the opposite strategy of favoring rapid development time over size. The microgastrine braconid Microplitis croceipes attacks partially concealed hosts and showed evidence of a trade-off between maximizing body size and minimizing development times. These results suggested that parasitoids attacking apparent, foliar-feeding hosts may favor rapid development time over size while parasitoids that attack concealed hosts favor size over development time. A broader survey of the literature supported the trends found in our experimental studies. The braconids and ichneumonids examined in this study also exhibit distinct differences in larval feeding and pupation behavior. These developmental traits did not appear to affect the size-development time continuum. However, these traits may affect the size range of hosts that larval endoparasitoids can successfully exploit.
\end{abstract}

Key words: Campoletis sonorensis; development, insect; herbivore, insect; insects; life history; Microplitis croceipes; parasitoid; Venturia canescens.

\section{INTRODUCTION}

The evolution of life history traits is influenced by both environmental factors and phylogenetic history. As a consequence, trait evolution almost always involves trade-offs between competing fitness functions (Stearns 1989, Lessells 1991, Abrams and Rowe 1996). Among the most important trade-offs is whether to grow larger at the cost of longer development time, or to develop more rapidly at the cost of reduced size. Studies from diverse taxa indicate that size is a primary target for selection, and that animals often allocate resources in ways that maximize this parameter. However, accelerated development at the cost of reduced size can be favored under conditions of high predation risks or limiting resources (Cole 1954, Schaffer 1974, Hirshfield and Tinkle 1975, Charlesworth 1980, Curio 1989). The slow growth-high mortality hypothesis (SG-HM), as originally conceived for insect herbivores (Clancy and Price 1987), similarly predicts that re-

Manuscript received 5 June 2000; revised 19 July 2001; accepted 4 October 2001; final version received 9 January 2002.

${ }^{2}$ Present address: Centre for Terrestrial Ecology, Netherlands Institute of Ecology, Heteren, The Netherlands. E-mail: harvey@cto.nioo.know.nl.

${ }^{3}$ Present address: Department of Entomology, 420 Biological Sciences, University of Georgia, Athens, Georgia 30602 USA. duced plant quality or allelochemicals will increase development time and mortality risks from natural enemies (Moran and Hamilton 1980, reviewed by Williams 1999). Evidence for mortality increasing with development time derives from several studies on insect herbivores that develop in exposed locations (Price et al. 1980, Grossmueller and Lederhouse 1985, Leather 1985, Benrey and Denno 1997). However, prolonged development times appear to have lower costs for species that feed in concealed sites, because risks of predation and parasitism are lower (Clancy and Price 1987, Craig et al. 1990, Johnson and Gould 1992).

The abundance and mortality risks faced by insect herbivores have long been thought to impact the evolution of fecundity in natural enemies (e.g., balanced mortality hypothesis) (Price 1973, 1974, 1980). In contrast, how host ecology might affect the development of third trophic level organisms is much less understood (Strand 2000). Parasitoid wasps are of particular interest in this regard, because all resources for development derive from feeding on one host individual. Parasitoids usually lay their eggs in (endoparasitoids) or on (ectoparasitoids) the bodies of insect herbivores, and their offspring develop by consuming host tissues or hemolymph. Most parasitoids develop in only a narrow range of host species and are only able to attack a particular life stage (egg, larva, pupa, or adult). En- 
doparasitoids that attack larval stage hosts are also referred to as koinobionts, because hosts continue to grow after being parasitized (Askew and Shaw 1986). Because of this interaction, hosts of koinobionts represent an open resource that can either be consumed rapidly by the developing parasitoid larva or that can increase in mass before being consumed to yield a larger parasitoid. Adult size has usually been considered the primary target for selection in parasitoids and that offspring should develop in ways that maximize this trait (Waage and Godfray 1985, King 1989, Mackauer and Sequeira 1993, Visser 1994, Mackauer et al. 1997). Yet, if the host dies before the parasitoid completes development, then the parasitoid also obviously dies. This intuitively suggests that selection should favor developmental strategies that maximize progeny survival to adulthood first and other traits secondarily. It also suggests that while increased size may be favored over development time in parastioids that face low mortality risks, rapid development time at the expense of size may be favored in parasitoids whose hosts confront high risks of predation.

Among the largest taxa of parasitoid wasps is the monophyletic superfamily Ichneumonoidea, which itself is divided into the families Ichneumonidae and Braconidae (Whitfield 1998, Quicke et al. 2000). The ichneumonid subfamily Campopleginae and braconid subfamily Microgastrinae are comprised exclusively of koinobiont endoparasitoids that attack larval stage herbivores in the order Lepidoptera (moths and butterflies). These parasitoids are very similar in size and commonly have overlapping host ranges. Yet, they also differ in two key developmental traits. Campoplegine ichneumonids obligately consume most or all host tissues and usually pupate after the host is consumed, while microgastrine braconids usually feed only on host hemolymph and emerge from the still living host to pupate externally (Gauld and Bolton 1988, Harvey et al. 2000).

In this study we examined the development of selected campoplegines and microgastrines in relation to host ecology and wasp feeding behavior. In the first part of this study, we measured development times, adult size, and host consumption by Venturia canescens Gravenhorst (Ichneumonoidea: Ichneumonidae, Campopleginae), Campoletis sonorensis Cameron (Ichneumonoidea: Ichneumonidae, Campopleginae), and $\mathrm{Mi}$ croplitis croceipes (Ichneumonoidea: Braconidae, Microgastrinae). We then conducted a survey to determine whether the broader literature supported the trends found in our experimental studies. Our results indicated that the developmental strategies of ichneumonoid koinobionts vary with the feeding ecology of their hosts. Larval feeding and pupation behavior of the parasitoid did not affect developmental strategies, but these traits could affect the size range of hosts that endoparasitoids can successfully parasitize.

\section{Methods \\ Biology of hosts and parasitoids}

All hosts and parasitoids were reared at $27^{\circ} \pm 2^{\circ} \mathrm{C}$, $65 \pm 5 \%$ relative humidity, and a 16:8 h light: dark photocycle. Each parasitoid used in the study was also solitary (i.e., a single offspring develops per host). Venturia canescens was obtained from a culture maintained for several years at Wageningen University, The Netherlands. It is a cosmopolitanly distributed parasitoid of Lepidoptera in the family Pyralidae. Host larvae feed almost exclusively in stored grains, nuts, and fruit (Harvey 1995). Most populations of $V$. canescens are comprised of asexual (thelytokous) individuals that obligately produce only female offspring. A female wasp locates concealed hosts by probing the substrate with its ovipositor. Upon contacting a host, the female pierces its cuticle and oviposits into the hemocoel. The parasitoid egresses from the host at the end of its larval development to spin a cocoon within the concealed, silken gallery constructed by the host. Adult emergence generally occurs 7-8 d later. For this study, V. canescens was reared on larvae of the Indian meal moth, Plodia interpunctella Hubner (Lepidoptera: Pyralidae), as outlined by Harvey and Thompson (1995). P. interpunctella was originally obtained from a culture maintained at Colorado State University, Fort Collins, Colorado, USA. Host larvae were reared in glass jars on diet consisting of a 5:1:1 mixture of cornmeal, yeast, and glycerol. Approximately 50 moths were added to jars after eclosion, and they were allowed to oviposit directly onto the diet.

Campoletis sonorensis was obtained from a culture maintained for many years at Texas A\&M University, College Station, Texas, USA. It is a Nearctic, sexually reproducing, parasitoid of $\sim 30$ macrolepidoptera in the family Noctuidae (Lindgren 1970). Hosts are all foliar feeders that develop in exposed locations. Females wasps locate hosts with their antennae and then rapidly oviposit into the host hemocoel. Unlike $V$. canescens, however, the mature parasitoid larva emerges and pupates on the host's food plant before the host has constructed a cocoon. Adult wasps emerge 5-6 d later. $C$. sonorensis was reared in the current study on larvae of the soybean looper, Pseudoplusia includens Walker (Lepidoptera: Noctuidae). Cultures of $P$. includens were originally obtained from Clemson University, Clemson, South Carolina, USA. Host larvae were reared in 30-mL plastic cups on artificial diet (Strand 1990). Moths were held in 4-L glass jars and fed a $20 \%$ sucrose solution. Female moths oviposited directly onto cotton netting used to cover the jars, which netting was secured by elastic bands. C. sonorensis was maintained in large Plexiglass boxes and a fed a $20 \%$ sucrose solution. Several adult female wasps were added to large Petri dishes $(20 \mathrm{~cm}$ diameter) containing $\sim 50$ second-third stadium $P$. includens larvae. After several hours exposure to hosts, parasitoids were returned to 
culture and parasitized hosts were isolated and reared in cups as described a few sentences earlier.

Microplitis croceipes was obtained from a culture maintained for several years at the University of Kentucky. Like $C$. sonorensis, it is also a Nearctic, sexually reproducing, parasitoid of noctuid Lepidoptera in the genera Heliothis and Helicoverpa (Lewis 1970, Powell and Elzen 1989). Females oviposit into the hemocoel of foliage feeding host larvae. However, toward the end of development of the parasitoid larva, the host leaves its host plant and burrows into the soil to form a pupal cell. The mature $M$. croceipes larva then emerges in this concealed location from the still living host by chewing a hole through the cuticle. The parasitoid larva spins a cocoon beside the host and the adult wasp emerges 5-6 d later. Here, M. croceipes was reared on larvae of the tobacco budworm, Heliothis virescens Fabricius (Lepidoptera: Noctuidae), which were also supplied by the University of Kentucky. Hosts and parasitoids were reared using the same methods described for $C$. sonorensis and $P$. includens.

All parasitoid females used in this study were mated and $<10 \mathrm{~d}$ old before being presented with hosts. Individual wasps were allowed to parasitize up to several hosts for the duration of the experiment.

\section{Determination of parasitoid size and development times}

$P$. interpunctella larvae undergo five or six instars (designated $L_{1}-L_{5}$ or $L_{6}$ ) before pupating (Harvey 1995). Last stadium larvae of $P$. interpunctella attain maximal larval masses between 20 and $35 \mathrm{mg}$ prior to pupation (Harvey 1995). For this study, $L_{2}-L_{5}$ hosts, weighing between $300 \mu \mathrm{g}$ and $35 \mathrm{mg}$, were presented individually to $V$. canescens in small plastic Petri dishes (4 cm diameter). Hosts were parasitized singly to assure that none were superparasitized. Hosts were then weighed on a Cahn 29 electrobalance (accuracy \pm 1 $\mu \mathrm{g}$; ThermoCahn, Madison, Wisconsin, USA) and reared in plastic vials $(8 \times 3 \mathrm{~cm})$ containing excess diet. Newly emerged adult $V$. canescens were killed by freezing and weighed on the Cahn electrobalance to determine their fresh body mass. Egg-to-adult development times were also recorded. After parasitoid emergence, both the host and parasitoid cocoons were carefully opened and the remaining head capsule and adjoining tissues of $P$. interpunctella larvae were weighed to compare the relationship between host size at parasitism and terminal host mass.

$P$. includens typically completes five instars before pupation and attains a maximum larval mass of 250$320 \mathrm{mg}$ (Strand 1990). Different instars of P. includens were determined by head capsule dimensions and fresh mass. $L_{1}-L_{5}$ hosts, weighing between $100 \mu \mathrm{g}$ and 80 $\mathrm{mg}$, were presented individually to mated $C$. sonorensis females in 4-cm Petri dishes. After being parasitized once, hosts were immediately weighed and reared singly in Petri dishes containing excess diet that was changed daily. At eclosion, adult wasp sizes and development times were recorded and the remaining host carcass was isolated and weighed. $H$. virescens complete five instars during development and attains a maximum mass of 400-500 mg before pupation (King and Hartley 1985). H. virescens was parasitized by M. croceipes females as described in the preceding section. Female wasps were allowed to parasitize $L_{1}-L_{5}$ hosts that weighed from $100 \mu \mathrm{g}$ to $350 \mathrm{mg}$. After parasitism, hosts were weighed and then transferred to plastic cups containing excess diet. Immediately following larval parasitoid egression, host larvae were killed by freezing and weighed. Adult parasitoid masses and egg-toadult development times were also recorded at eclosion.

Preliminary analysis of the data obtained for each parasitoid-host system indicated that offspring size and final host sizes increased nonlinearly with initial host size at oviposition. As a result, initial host size data were $\log$ transformed. We used analysis of covariance (ANCOVA) to detect sex-differential effects of host size and development time. The relative importance of adult size or development time for parasitoid fitness was determined by parasitizing hosts that differed in their initial size and comparing the variation in size and development time of the resulting progeny. Evidence that size was favored over development time would be if offspring size was similar across all host sizes, but development times were significantly longer in small vs. large hosts. Evidence that development time was favored over size would be if development times were similar among host sizes but parasitoid size was significantly smaller in small vs. large hosts. Evidence for a trade-off between size and development time would be if progeny size significantly increased and development times significantly decreased with host size (Mackauer and Sequeira 1993, Harvey et al. 2000).

\section{Development of other ichneumonids and braconids}

Comparative data on development of koinobiont ichneumonids and braconids were obtained by surveying the literature. Only studies on solitary species of parasitoids were included. A total of 33 parasitoid-host associations were identified that contained information on parasitoid size and development time in relation to host size (or instar) and feeding behavior. The relative importance of size or development time for fitness of each parasitoid species was made by comparing the variation in these parameters in relation to host size as described in the preceding paragraph. Comparisons of species in different taxa often requires special statistical approaches since differences could be confounded by phylogenetic differences (Felsenstein 1985, Harvey and Pagel 1990). However, this does not apply here as ichneumonids and braconids form a monophyletic assemblage and share a common ancestor (Whitfield 1998). Therefore, interactions between parasitoid fam- 
TABLE 1. Development characteristics of the parasitoids Venturia canescens, Campoletis sonorensis, and Microplitis croceipes in their respective host species.

\begin{tabular}{|c|c|c|c|c|c|c|}
\hline $\begin{array}{l}\text { Parasitoid species } \\
\text { (Family) }\end{array}$ & $\begin{array}{l}\text { Host species } \\
\text { (Family) }\end{array}$ & $N$ & $\begin{array}{l}\text { Max. mass of } \\
\text { nonparasitized } \\
\text { hosts }(\mathrm{mg}) \dagger\end{array}$ & $\begin{array}{c}\text { Size range } \\
\text { of parasitized } \\
\text { host }(\mathrm{mg})\end{array}$ & $\begin{array}{l}\text { Size range of } \\
\text { adult parasitoids } \\
(\mathrm{mg})\end{array}$ & $\begin{array}{l}\text { Max. parasit- } \\
\text { ized host mass/ } \\
\text { max. mass of } \\
\text { unparasitized } \\
\text { host } \ddagger\end{array}$ \\
\hline $\begin{array}{l}\text {. canescens } \\
\text { (Ichneumonidae) }\end{array}$ & $\begin{array}{l}\text { P. interpunctella } \\
\text { (Pyralidae) }\end{array}$ & 57 & $26.7 \pm 1.2$ & $0.3-34.3$ & $4.1-7.2$ & 100 \\
\hline $\begin{array}{l}\text { C. sonorensis } \\
\text { (Ichneumonidae) }\end{array}$ & $\begin{array}{l}\text { P. includens } \\
\text { (Noctuidae) }\end{array}$ & 80 & $279.37 \pm 5.33$ & $0.1-66.0$ & $2.6-6.9$ & 23.6 \\
\hline $\begin{array}{l}\text { M. croceipes } \\
\text { (Braconidae) }\end{array}$ & $\begin{array}{l}\text { H.virescens } \\
\text { (Noctuidae) }\end{array}$ & 69 & $414.9 \pm 19.2$ & $0.11-352.9$ & $4.4-7.2$ & 85.1 \\
\hline
\end{tabular}

$\dagger$ Mass data are mean \pm 1 SE. Sample size for all controls (unparasitized larvae) $=10$.

$\$$ This figure describes the mass ratio of the body mass of the largest host successfully parasitized (producing an adult wasp) against the mean maximum mass of controls.

ily (Ichneumonidae, Braconidae), host feeding location (exposed or concealed), and parasitoid developmental strategy (size, development time, or a trade-off between these traits) were examined using conventional $G$ tests.

\section{RESUlts}

As previously discussed, most koinobionts encounter larval stage hosts of different instars that vary greatly in size. If oviposition occurs in small hosts, progeny can either consume the host rapidly, at the potential cost of reduced size, or it can delay consumption of the host (i.e., exhibit a lag phase) which ultimately results in a larger host and a bigger parasitoid, but at the cost of longer development times. The outcomes of experiments with $V$. canescens, $C$. sonorensis, and $M$. croceipes are summarized in Table 1 and Figs. 1-4.

Venturia canescens maximizes size at the cost of increased development time in Plodia interpunctella

$V$. canescens developed successfully in $L_{2}-L_{5} P$. interpunctella that ranged from $330 \mu \mathrm{g}$ to $34.3 \mathrm{mg}$ at oviposition (Table 1). Females failed to locate and oviposit in $L_{1}$ hosts weighing $<200 \mu \mathrm{g}$. Females occasionally detected and attempted to parasitize $L_{1}$ hosts by jabbing their ovipositor at them, but hosts were never stung due to their small size. Parasitoids that emerged from hosts weighed 4.12-7.24 mg (mean $5.6 \pm 0.09$ $\mathrm{mg}$ ) and their size was unaffected by host size at oviposition $\left(F_{1,55}=305, P=0.09, r^{2}=5.30\right)$ (Fig. 1a). This indicated that $V$. canescens progeny attain a similar adult size regardless of a host's initial size. In contrast, development time from egg to adult emergence decreased significantly with host size at oviposition $\left(F_{1,55}\right.$ $=77.08, P<0.001, r^{2}=58.40$ ) (Fig. 1b). Development times for $V$. canescens ranged from 19 to $26 \mathrm{~d}$ (mean $20.8 \pm 0.24 \mathrm{~d}$ ) with offspring from hosts parasitized as second instars taking 5-7 d longer to develop than wasps from hosts parasitized as fifth instars.

Hosts parasitized by $V$. canescens continued to feed and grow until the parasitoid larva shifted from hemolymph feeding to consumption of tissues. Con- sumption of host tissues always occurred after the parasitoid larva molted to its final instar (Harvey 1995). $V$. canescens consumed the entire host, leaving uneaten only the host's head capsule and cuticle. Initial host mass varied positively with the terminal mass of the host carcass $\left(F_{1,32}=20.26, P<0.001, r^{2}=38.50\right)$ (Fig. 1c). Dividing the mass of the adult parasitoid by the combined final mass of the host and parasitoid yielded an estimate of the proportion of host resources used by $V$. canescens. The proportion of host resources consumed by $V$. canescens decreased significantly with initial host size $\left(F_{1,31}=11.66, P=0.002, r^{2}=27.40\right)$. However, this trend is unlikely of great biological significance as $V$. canescens consumed $>95 \%$ of the host irrespective of its initial size at parasitism (Fig. 1d). Based on these results, we defined the threshold for small and large hosts as $\pm 15 \mathrm{mg}$. We found no difference in the percentage of $V$. canescens $(\sim 75 \%)$ that survived to adulthood in these two size classes of hosts (Yates-corrected $\chi^{2}=0.03$, df $=1, P>0.05$ ) (Fig. 4).

\section{Campoletis sonorensis minimizes development time} at the cost of size in Pseudoplusia includens

The mass of hosts successfully parasitized by $C$. sonorensis ranged from $96 \mu \mathrm{g}$ to $66 \mathrm{mg}$ (Table 1). C. sonorensis oviposited into $P$. includens larvae up to 78 $\mathrm{mg}$ in size but the progeny always died in these very large hosts before pupating. The effect of offspring sex on adult parasitoid size and development time was examined using ANCOVA, because no significant differences were found in the regression lines for male and female wasps (size: $t=1.21, \mathrm{df}=66, P>0.05$; development time: $t=0.26$, df $=66, P>0.05)$. Adult parasitoid size covaried significantly with host size $(F$ $=15.96, \mathrm{df}=1,77, P<0.001)$ and offspring sex $(F$ $=6.45 \mathrm{df}=1,77, P=0.01)$ with females on average weighing more $(4.5 \pm 0.14 \mathrm{mg})$ than males $(3.9 \pm 0.14$ mg) (Fig. 2a). In contrast, wasp development time was unaffected by initial host size $(F=2.16$, df $=1,77$, $P=0.15)$ and did not covary with offspring sex $(F=$ 0.16, df $=1,77, P=0.69$ ) (Fig. 2b). Development 

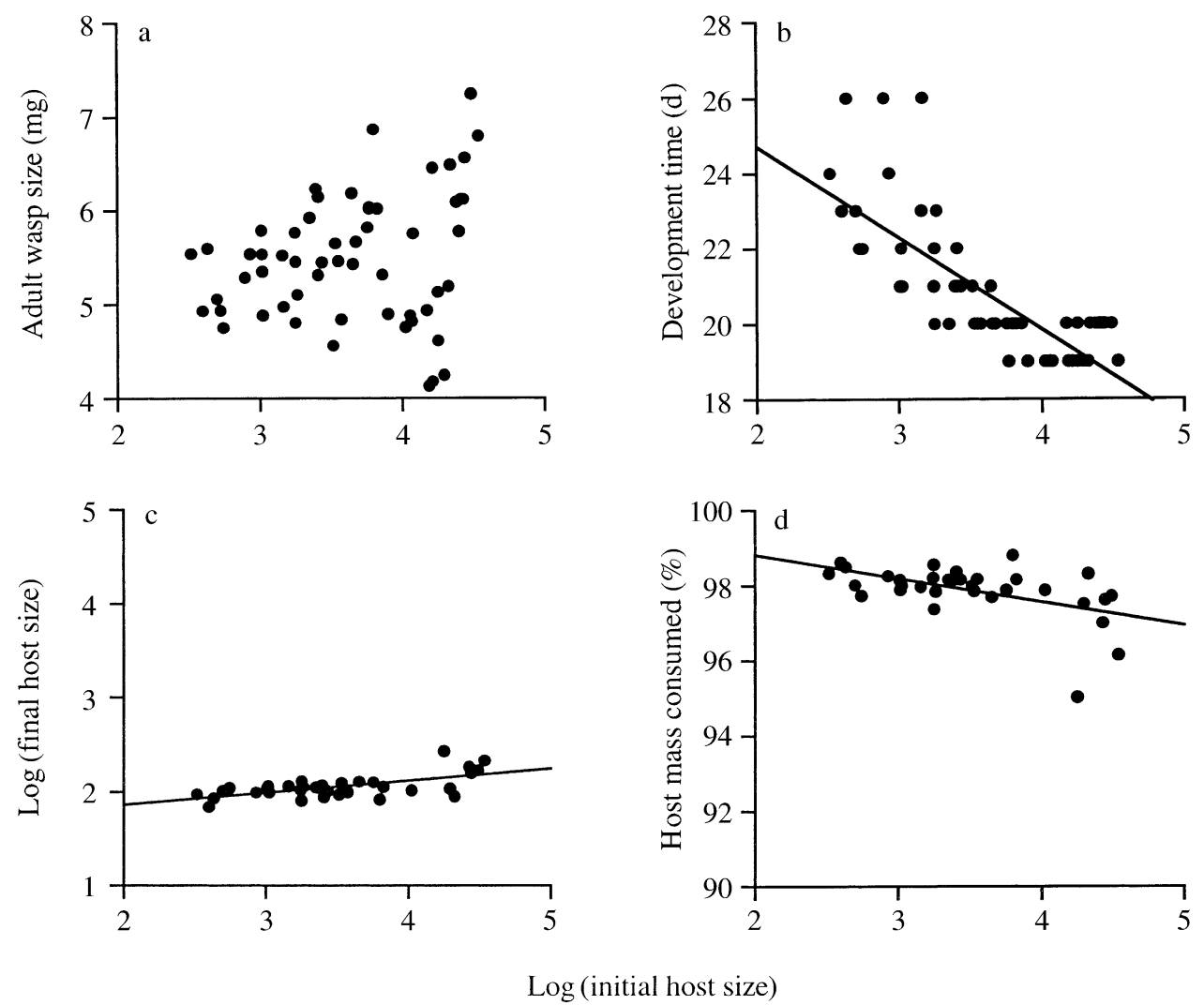

FIG. 1. Relationships between the size of Plodia interpunctella larvae and developmental traits in Venturia canescens. (a) Relationship between host size at oviposition and adult female size at eclosion. The regression equation is: wasp size $=$ 0.27 (log host size) $+4.50, n=57$ parasitoid individuals. (b) Relationship between host size at oviposition and egg-to-adult development time. The regression equation is: development time $=29.55-2.41(\log$ host size $), n=57$ parasitoid individuals. (c) Relationship between initial host size and final host size at parasitoid emergence. The regression equation is: log final host size $=0.13(\log$ initial host size $)+1.60, n=34$ parasitoid individuals. (d) Relationship between initial host size and the percentage of host mass consumed by parasitoid offspring, i.e., parasitoid mass/(final host mass + parasitoid mass). The regression equation is: percentage consumed $=100.05-0.62(\log$ initial host size $), n=34$ parasitoid individuals.

time in C. sonorensis varied from 13 to $20 \mathrm{~d}$ (female mean $=14.9 \pm 0.22 \mathrm{~d}$, male mean $=15.1 \pm 0.27 \mathrm{~d})$.

The largest hosts parasitized by $C$. sonorensis (30 $\mathrm{mg}$ at oviposition) gained little, if any, mass after parasitism. In contrast, smaller hosts continued to feed and grow, albeit at a reduced rate compared with nonparasitized hosts, up to $24 \mathrm{~h}$ before parasitoid pupation. Final host size varied positively with initial host size $\left(F=20.71\right.$, df $\left.=1,28, P<0.001, r^{2}=42.50\right)$ (Fig. $2 \mathrm{c})$, but overall the final masses attained by hosts were very similar (2.8-3.2 mg). C. sonorensis consumed most of the host before pupating adjacent to the host carcass. The proportion of host resources used by $C$. sonorensis decreased with host size at oviposition ( $F$ $=12.39$, df $=1,29, P<0.001, r^{2}=29.90$ ) (Fig. $2 \mathrm{~d}$ ). Using a threshold $\pm 30 \mathrm{mg}$ for large and small hosts, parasitoid larvae consumed $>90 \%$ of hosts that were small at oviposition, and $\sim 80 \%$ of hosts that were large. Correspondingly, more $C$. sonorensis survived to adulthood in small hosts than large (pooled sex data: Yates-corrected $\chi^{2}=4.02$, df $=1, P<0.05$ ) (Fig. 4).
Microplitis croceipes exhibits a trade-off in fitness between size and development time in

Heliothis virescens

Of the three parasitoid species studied here, $M$. croceipes successfully parasitized the widest range of host sizes. The smallest host to produce an adult wasp was a first instar weighing $107 \mu \mathrm{g}$ at oviposition and the largest was a fifth instar weighing $351 \mathrm{mg}$. Plotting wasp size against initial host size revealed significant differences in the slopes of the regression lines for males and females $(t=2.05$, df $=61, P<0.05)$, but we detected no differences between the sexes in development time as a function of initial host size $(t=$ 0.39 , df $=61, P>0.05)$. We therefore used ANCOVA for the development time data and separate regression analyses for male and female wasps to analyze the relationship between host and offspring size. Adult parasitoid size increased slightly but significantly with host size for male wasps $(F=11.85$, df $=1,42, P<$ $0.01, r^{2}=22.00$; Fig. 3a), but not females $(F=0.17$, 

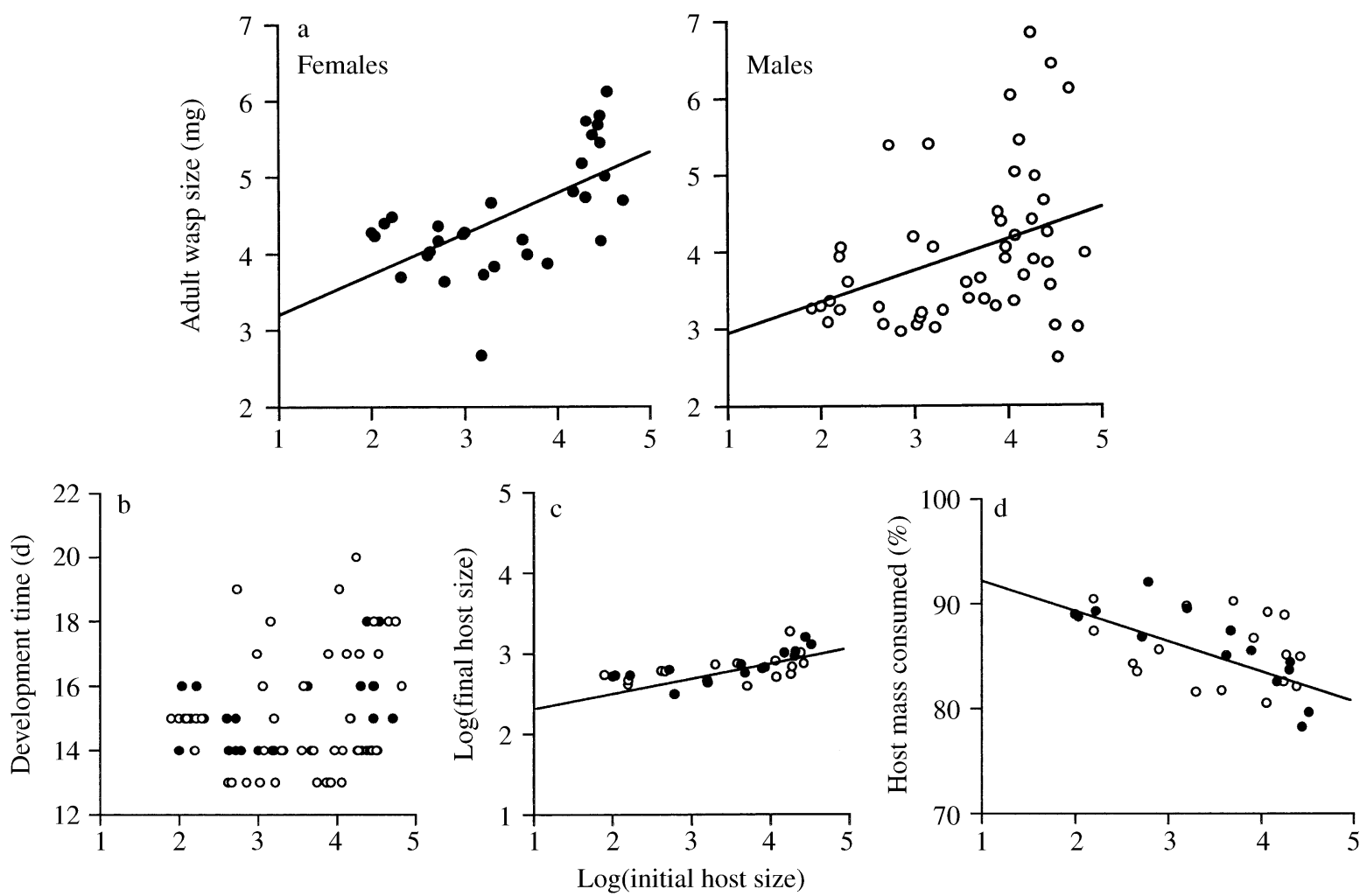

FIG. 2. Relationships between the size of Pseudoplusia includens larvae and developmental traits in Campoletis sonorensis. (a) Relationship between host size at oviposition and adult female (solid circles) and male (open circles) size at eclosion. Host size similarly affected parasitoid size in both sexes, although females were larger: female wasp size $=0.53$ (log host size $)+2.67, n=31$ parasitoid individuals; male wasp size $=0.41(\log$ host size $)+2.54, n=49$ parasitoid individuals. (b) Relationship between host size at oviposition and adult female (solid circles) and male (open circles) egg-to-adult development time: female development time $=0.24(\log$ host size $)+14.12, n=31$ parasitoid individuals; male development time $=$ $0.43(\log$ host size $)+13.55, n=49$ parasitoid individuals. (c) Relationship between initial host size and final host size at parasitoid emergence. Hosts contained either female (solid circles) or male (open circles) wasp offspring. The pooled regression equation is $\log$ final host size $=0.14(\log$ initial host size $)+2.35, n=31$ parasitoid individuals. (d) Relationship between initial host size and the percentage of host mass consumed by parasitoid offspring, i.e., parasitoid mass/(final host mass + parasitoid mass). Hosts contained either female (closed circles) or male (open circles) offspring. The pooled regression equation is: percentage consumed $=93.82-2.33(\log$ initial host size $), n=31$ parasitoid individuals.

df $=1,22, P=0.69, r^{2}=0.80$; Fig. 3a). However, M. croceipes laid fewer fertilized (=female) eggs in small hosts than large, which may account for this discrepancy. The average size of adult female (5.6 \pm 0.11 $\mathrm{mg})$ and male $(5.4 \pm 0.06 \mathrm{mg})$ offspring did not significantly differ. Total development time covaried significantly with host size $(F=6.92$, df $=1,65, P<$ $\left.0.05, r^{2}=6.10\right)$ and offspring sex $(F=6.50$, df $=1$, $65, P<0.05)$. Development time decreased slightly but significantly with initial host size, and on average female wasps took longer to develop $($ mean $=17.1 \pm$ $0.31 \mathrm{~d})$ than males $($ mean $=16.3 \pm 0.27 \mathrm{~d})$.

Hosts weighing up to $100 \mathrm{mg}$ at oviposition continued to feed and grow during parasitism, although the rate of growth declined with host size. Large hosts on the other hand ceased feeding within hours of parasitism and usually lost considerable mass before emergence of $M$. croceipes. Despite these trends, the larger the host was at oviposition, the higher its final mass
$\left(F=253.23, \mathrm{df}=1,60, P<0.001, r^{2}=79.90\right)($ Fig. $3 c)$. Regardless of size at oviposition, however, parasitized $H$. virescens always burrowed into the substrate to form a pupal cell before the parasitoid offspring emerged and spun a cocoon. There was a highly significant relationship between final host size and the percentage of host mass consumed by the parasitoid larva $\left(F=272.47, \mathrm{df}=1,60, P<0.001, r^{2}=82.0\right)$ (Fig. 3d). Yet, regardless of host size, M. croceipes consumed only a small proportion (3-12\%) of available host resources, because of its habit of feeding only on hemolymph. Since $M$. croceipes was able to parasitize much larger hosts than the other two parasitoid species, the size threshold between "large" and "small" hosts was also deemed to be considerably higher. We designated this threshold as $100 \mathrm{mg}$ since this was the approximate division between the average mass of fourth and fifth instar hosts. Parasitoid survival to adulthood did not significantly differ between large and 


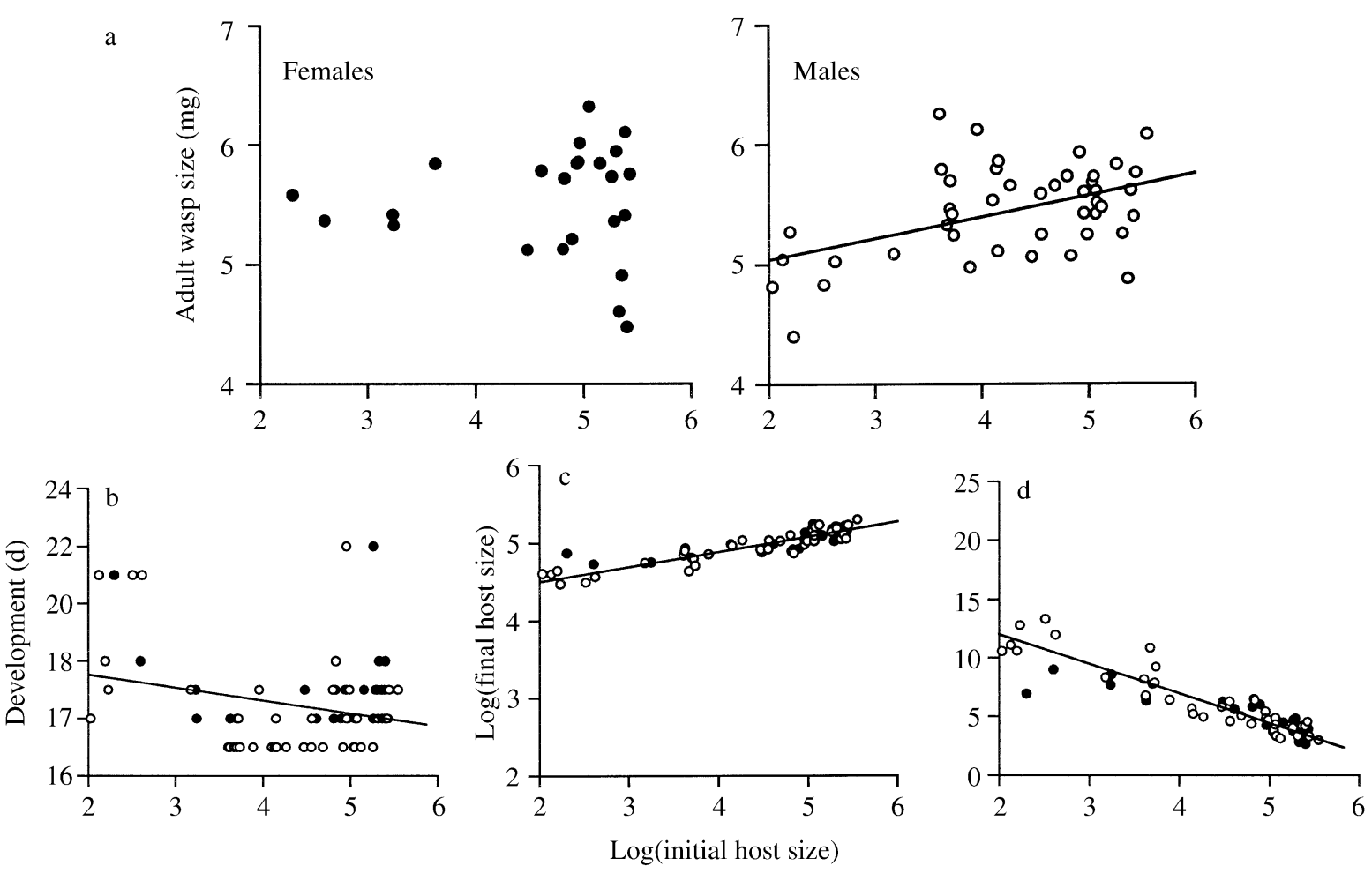

FIG. 3. Relationships between the size of Heliothis virescens larvae and developmental traits in Microplitis croceipes. (a) Relationship between host size at oviposition and adult female (solid circles) and male (open circles) size at eclosion. Female wasp size $=0.05(\log$ host size $)+5.36, n=25$ parasitoid individuals; male wasp size $=0.18(\log$ host size $)+4.68$, $n=44$ parasitoid individuals. (b) Relationship between host size at oviposition and adult female (solid circles) and male (open circles) egg-to-adult development time. Host size affected female and male development time similarly. Development time $=18.52-0.43(\log$ host size $), n=69$ parasitoid individuals. (c) Relationship between initial host size and final host size at parasitoid emergence. Hosts contained either female (solid circles) or male (open circles) wasp offspring. The pooled regression equation is: $\log$ final host size $=0.18(\log$ initial host size $)+4.20, n=61$ parasitoid individuals. (d) Relationship between initial host size and the percentage of host mass consumed by parasitoid offspring (parasitoid mass/final host mass + parasitoid mass). Hosts contained either female (closed circles) or male (open circles) offspring. The pooled regression equation is: percentage consumed $=16.04-2.29$ (log initial host size), $n=62$ parasitoid individuals.

small hosts (pooled sex data: Yates-corrected $\chi^{2}=2.25$, df $=1, P>0.05$ ) (Fig. 4).

\section{Developmental strategies of other ichneumonid and braconid koinobionts}

Our survey of the literature identified data for 12 ichneumonid- and 21 braconid-host associations that contained data on parasitoid size and development times in hosts of different size (or instar). Table 2 presents whether the host developed in an exposed or concealed site, and whether the parasitoid exhibited a developmental strategy that favored size, development time, or a trade-off between these fitness traits. Hosts were classified as exposed if they fed on exposed foliage or in concealed locations like stems, seeds, or fruit. Using these associations, we found that parasitoid family $(p)$, host feeding location $(h)$, and developmental strategy $(d)$ were not independent $\left(G_{\mathrm{T}}=45.0\right.$, df $=7, P<0.05)$. The interactions between developmental strategy and host feeding location $\left(G_{h d}=80.1\right.$, $\mathrm{df}=2, P<0.05)$, as well as parasitoid family and host feeding location $\left(G_{p h}=26.6, \mathrm{df}=1, P<0.05\right)$ were highly significant. This indicated that the developmental strategies of ichneumonid and braconid koinobionts differed with host feeding site. For the parasitoids that attacked exposed herbivores, 15 clearly favored short development time over size. Nine others exhibited a trade-off strategy whereby progeny from small, early instar, hosts took longer to develop and were smaller than progeny from large hosts. In contrast, seven of the eight parasitoids that attacked concealed hosts favored size over development time (Table 2). Although the feeding behavior of campoplegine ichneumonids (tissue) and microgastroid braconids (hemolymph) differ, we found no significant interaction between parasitoid family and developmental strategy $\left(G_{p d}=5.2, \mathrm{df}=2, P>0.05\right)$. However, differences in the feeding of parasitoid larvae could influence the size range of hosts these parasitoids attack. As previously noted, the microgastrine $M$. croceipes successfully parasitized a much wider range of host sizes than $V$. canescens or C. sonorensis (see Figs. 1-3). We were 


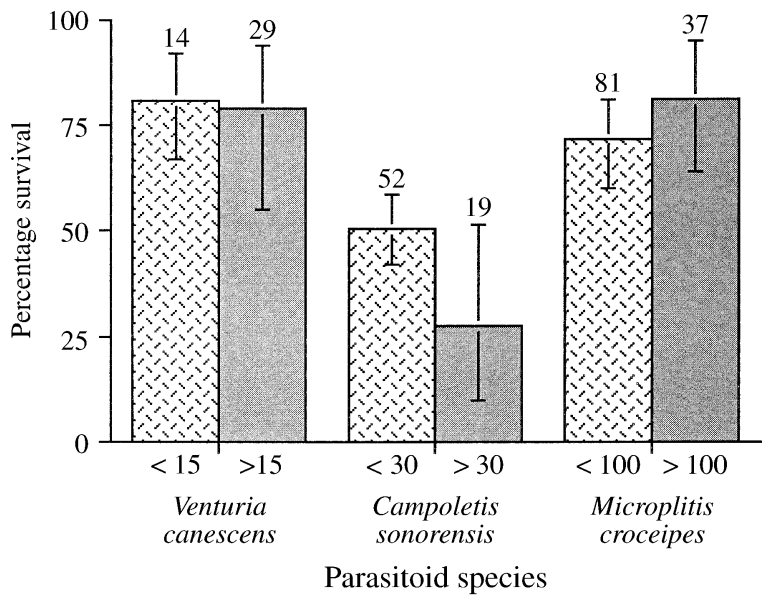

FIG. 4. Percentage survival (mean and 95\% confidence interval) to adult stage for Venturia canescens $(n=71$ parasitoid individuals), Campoletis sonorensis $(n=181$ parasitoid individuals), and Microplitis croceipes ( $n=118$ parasitoid individuals) in large (shaded bars) and (basket-weave bars) hosts of their respective host species. Numbers above the histogram bars are numbers of successfully emerged parasitoids within the size ranges specified. The threshold between the two size categories (in $\mathrm{mg}$ ) was determined on the basis of host growth potential and the size range of hosts habitually attacked by each parasitoid species.

unable to analyze this trend among the species presented in Table 2, because in many of these studies only host instars (rather than initial host size) were reported. However, our own studies (Harvey et al. 1999, 2000) suggest that hemolymph feeding braconids parasitize a much larger size range of hosts than tissue feeding ichneumonids.

Based on the experimental and comparative data presented here, we developed simple graphical models to illustrate the development of koinobiont parasitoids that attack exposed and concealed hosts (Fig. 5). In these models, we assumed that parasitoids can oviposit in hosts of different initial size (small-large) and/or instar ( $x$-axis). Parasitoid development time is plotted below the $x$-axis while offspring size is plotted along the $y$-axis. The growth phase of parasitoid larvae is illustrated as a continuously increasing exponential curve with a sharp cutoff. All studies in the literature we are aware of indicate that parasitoid growth conforms to this function (Mackauer and Sequeira 1993, Harvey 1995, Harvey et al. 2000). Parasitoids of concealed hosts, like $V$. canescens, maximize size at the expense of development time (Fig. 5a). Progeny size is similar across the range of host sizes that are parasitized, but development times are longer in small hosts than in large hosts. This is because progeny delay consumption of available host resources in small and medium hosts until their host achieves a larger mass. In contrast, parasitoids of exposed hosts, like C. sonorensis, develop at a constant rate that is independent of initial host size (Fig. 5b). This results in uniformly rapid development times but progeny from small hosts are on average smaller than those from large hosts. Endoparasitoids, like $M$. croceipes, exhibit a trade-off between development time and size as evidenced by development times being longer and progeny being smaller in small hosts vs. large hosts (Fig. 5c).

\section{Discussion}

Body size has often been considered the most important determinant of life history variation in both vertebrates and invertebrates (Calder 1984, King 1989, Stearns 1989). Yet, the intimate relationship that exists between third trophic level organisms, like parasitoids, and their insect hosts suggest several reasons why body size may not always be the primary target for selection. Among the most important of these are the mortality risks faced by insect herbivores, which if parasitized, confer a similar risk on a developing parasitoid (Price 1980, Blackburn 1991). Focusing on ichneumonoids that parasitize larval Lepidoptera, our results indicate that developmental strategies differ between wasps that parasitize exposed and concealed hosts.

If size is the primary target for selection, we would assume that koinobionts laid in host larvae of suboptimal size should delay their development until the host attains an optimal size or quality value. Our results with Venturia canescens conform well to this assumption since offspring always exhibit a lag phase in development when laid in smaller hosts. This results in adult wasps of similar size but development times that are always longer in small hosts than large hosts. In contrast, the closely related campoplegine Campoletis sonorensis exhibited exactly the opposite strategy of minimizing development time at the cost of size. Intermediate between these extremes was the microgastrine braconid Microplitis croceipes, which showed evidence of a trade-off between size and development time. The most obvious difference between these parasitoid-host associations was the apparency of the host larvae. $V$. canescens exclusively parasitizes well-concealed pyralid larvae, $C$. sonorensis parasitizes noctuid larvae that feed on exposed foliage, and $M$. croceipes parasitizes noctuid larvae of intermediate apparency that feed on exposed foliage but that burrow into the soil before parasitoid emergence. The influence of host apparency on developmental strategies of ichneumonoids is also supported by our survey of the literature. Ichneumonids and braconids that attacked external, foliar feeding hosts either favored short development time over size, or exhibited a trade-off between these traits. In contrast, species that attacked concealed hosts almost always favored size over development time. Based on these results, we conclude that the importance of size and development time for fitness of koinobiont ichneumonoids varies with host feeding ecology, which in turn is likely correlated with mortality risks.

In developing the balanced mortality and slow growth-high mortality hypotheses, Price (1974) and 
TABLE 2. The relationship between the feeding ecology of the host species and the developmental strategies of solitary koinobiont endoparasitoids in selected ichneumonid and braconid wasps.

\begin{tabular}{|c|c|c|c|c|}
\hline Parasitoid species & Host species & Apparency & $\begin{array}{l}\text { Favored } \\
\text { strategy }\end{array}$ & Reference \\
\hline \multicolumn{5}{|l|}{ Ichneumonidae } \\
\hline Venturia canescens & Plodia interpunctella & concealed & size & this study \\
\hline Venturia canescens & Anagasta kuehniella & concealed & size & Harvey and Vet (1997) \\
\hline Diadegma chrysostictos & Plodia interpunctella & concealed & size & J. A. Harvey (unpublished data) \\
\hline Campoletis sonorensis & Pseudoplusia includens & exposed & DT & this study $T$ \\
\hline Campoletis sonorensis & Heliothis virescens & exposed & DT & Gunasena et al. (1989) \\
\hline Campoletis flavicincta & Spodoptera frugiperda & exposed & DT & Patel and Habib (1987) \\
\hline Hyposoter exiguae & Heliothis virescens & exposed & Comp & Campbell and Duffey (1979) \\
\hline Hyposoter exiguae & Trichoplusia ni & exposed & Comp & Jowyk and Smilowitz (1978) \\
\hline Hyposoter exiguae & Manduca sexta & exposed & DT & Beckage and Templeton (1985) \\
\hline Hyposoter fugitivus & Manduca sexta & exposed & $D T$ & Beckage and Templeton (1985) \\
\hline Trathala flavoorbitaalis & Leucinodes orbonalis & concealed & Comp & Sandanayake and Edirisinghe (1992) \\
\hline Tranosema rostrale & Choristoneura fumiferana & exposed & DT & Cusson et al. (1998) \\
\hline \multicolumn{5}{|l|}{ Braconidae } \\
\hline Cotesia rubecula & Pieris rapae & exposed & DT & Harvey et al. (1999) \\
\hline Cotesia urabae & Uraba lugens & exposed & Comp & Allen and Keller (1991) \\
\hline Cotesia marginiventris & Heliothis virescens & exposed & Dtime & Bolling and Pitre (1970) \\
\hline Cotesia medicaginis & Colias eurytheme & exposed & Dtime & Allen (1958) \\
\hline Dolichogenidea eucalypti & Uraba lugens & exposed & Comp (?) & Allen and Keller (1991) \\
\hline Apanteles carpatus & Tineola bisselliella & concealed & size & Harvey et al. (2000) \\
\hline Apanteles galleriae & Galleria mellonella & concealed & size & Wani et al. (1994) \\
\hline Microplitis demolitor & Pseudoplusia includens & exposed & DT & Harvey et al. (2000) \\
\hline Microplitis demolitor & Heliothis virescens & exposed & DT & Strand et al. (1988) \\
\hline Microplitis mediator & Pseudoplusia includens & exposed & DT & J. A. Harvey (unpublished data) \\
\hline Microplitis mediator & Leucania separata & exposed & DT & Tanaka et al. (1984) \\
\hline Microplitis croceipes & Heliothis virescens & exposed $\dagger$ & Comp & this study \\
\hline Microplitis rufiventris & Spodoptera littoralis & exposed & DT & Hegazi et al. (1988) \\
\hline Ephedrus californicus & Acyrthosiphon pisum & exposed & Comp & Sequeira and Mackauer (1993) \\
\hline Aphidius sonchi & Hyperomyzus lactucae & exposed & DT & Liu (1985) \\
\hline Aphidius ervi & Acyrthosiphon pisum & exposed & DT & Sequeira and Mackauer (1992a,b) \\
\hline Opius dissitus & Liriomyza sativae & concealed & size & Pettit and Wieslebach (1993) \\
\hline Dacnusa sibirica & Liriomyza sativae & concealed & size & Croft and Copland (1995) \\
\hline Meterous trachynotus & Choristoneura fumiferana & exposed & Comp & Hebert and Cloutier (1990) \\
\hline Cardiochiles nigriceps & Heliothis virescens & exposed & Comp & Pennachio et al. (1994) \\
\hline Cardiochiles diaphaniae & Diaphania hyalinata & exposed & Comp & Smith et al. (1994) \\
\hline
\end{tabular}

Note: Size, development time (DT), and compromise between these traits (Comp) are defined as favored strategies on the basis of variation estimates in these parameters across a range of host sizes or stages at parasitism.

$\dagger H$. virescens parasitized by $M$. croceipes feed in exposed locations but burrow into a concealed location prior to parasitoid emergence.

Clancy and Price (1987) similarly stressed the importance of herbivore ecology in assessing mortaility risks. Experimental data supporting this assumption include mortality schedules, which are known to vary among herbivores that feed in exposed and concealed locations (Cornell 1990, Denno and Benrey 1997, Williams 1999). Studies of parasitoid species loads also underscore the importance of host feeding niche for host mortality and intraguild competition among natural enemies. In their survey of the literature, Hawkins and Lawton (1987) and Hawkins (1988) determined that external foliar feeders, leaf rollers, and leaf miners had much higher parasitoid species loads than galler, borer, and root feeding species. Blackburn (1991) also amassed data from the literature on 474 species of parasitoids from diverse taxa in an effort to identify correlations between life history traits and ecological variables. While the phylogenetic relationships among the species in this large data set were often unclear, it is interesting to note that one of the few significant re- lationships detected was that species attacking exposed hosts exhibited shorter development times than those attacking concealed hosts. Correlations clearly do not indicate causality, but collectively these studies support our own conclusion that host feeding ecology strongly affects mortality risks and the developmental strategies of parasitoids.

Relatively few studies have attempted to directly measure the mortality risks faced by parasitoids and other third trophic level organisms in the field. Nonetheless, several lines of evidence indicate that parasitoids often experience high mortality risks. First, it is well known that parasitoids are susceptible to many of the same pathogens that infect their hosts (Brooks 1993). Parasitoids are also known to experience high levels of intraguild predation via hyperparasitoids, other primary parastioids (via multiparasitism), and generalist predators (Rosenheim et al. 1995, Rosenheim 1998, Brodeur 2000). These risks appear to be especially high for koinobionts, which are almost always 

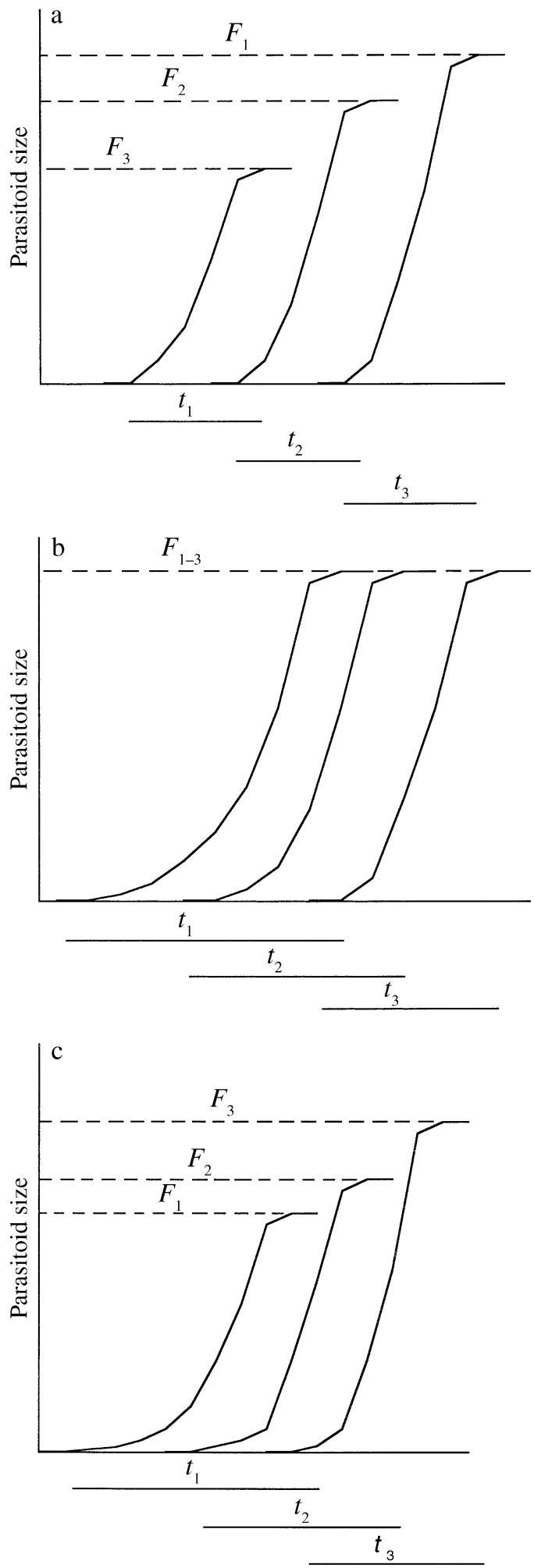

Host size/age; time

FIG. 5. Graphical models illustrating the developmental strategies of koinobiont endoparasitoids that parasitize larval stage hosts of varying initial size (small, medium, and large). (a) Parasitoids attacking exposed foliar-feeding hosts exhibit uniform development times $\left(t_{1}-t_{3}\right)$ in hosts of different initial competively inferior to idiobionts like ectoparasitoids and most hyperparasitoids (Varley 1947, Askew 1975, Shaw 1994, Stiling and Rossi 1994). Focal observation and cage studies similarly suggest that both immature and adult parasitoids that exist in exposed locations experience heavy predation (Rees and Onsager 1982, Ferguson and Stiling 1996, Heimpel et al. 1997). Finally, adaptations in addition to rapid development time indirectly suggest that parasitoids have evolved under selection pressures exerted by risks of predation. For example, koinobionts often induce changes in the feeding activity, microhabitat preferences, and defensive behavior of hosts that decrease their likelihood of being encountered by predators or other parasitoids (Brodeur and McNeil 1992, Adamo 1997).

We originally thought that differences in feeding and pupation might result in differences in whether campoplegine ichneumonids and microgastroid braconids favor large size or rapid development time. Our results do not indicate this to be the case, but we do note that tissue and hemolymph feeding may affect the size range of hosts that larval endoparasitoids can attack. The suitable range of host sizes attacked by $C$. sonorensis was considerably narrower than was demonstrated by $M$. croceipes. The latter species successfully parasitized hosts weighing up to $350 \mathrm{mg}$, or $>80 \%$ of the growth potential of healthy host larvae, whereas $C$. sonorensis could only exploit hosts growing up to $\sim 60$ $\mathrm{mg}$, or $<25 \%$ of their growth potential. The narrower size range of hosts parasitized by tissue feeding campoplegines likely reflects the requirement that these parasitoids must consume most host tissues to successfully pupate (Harvey et al. 2000, Strand 2000). In contrast, hemolymph feeding and external pupation greatly reduce the risks offspring face when developing in hosts larger than themselves since consumption of the host is not required for survival. One consequence of this dichotomy is that hemolymph feeding has potentially facilitated host range shifts toward larger species and to the evolution of gregariousness by microgastroids (Strand 2000). Another is that differences in host feeding behavior could affect competitive interactions between campoplegines and microgastroid braconids since the host ranges of wasps in these taxa overlap greatly in nature (Lindgren 1970, Jones and Lewis 1971, Gauld 1988, Gauld and Bolton 1988).

$\leftarrow$

size but offspring size $\left(F_{1}-F_{3}\right)$ is reduced in small vs. large hosts. Fitness as measured by development time, therefore, is favored over size. (b) Parasitoids attacking concealed hosts (e.g., root-feeding or gall-forming insects) attain a similar size in hosts of different initial size, but development times are longer in small hosts vs. large hosts. Here, fitness as measured by size is favored over development time. (c) Parasitoids exhibiting a trade-off between development time and size. Development time decreases while offspring size increases with initial host size. This strategy suggests that the two measures of fitness are balanced in determining the optimal phenotype. 
In reviewing the literature, Abrams and Rowe (1996) describe how the development of many organisms is affected by predation risks. For example, Martin (1995) reported that North American land birds nesting in the open suffer higher risks of early predation and exhibit shorter development times between egg hatch and fledging than birds that nest in concealed tree cavities. Vollrath and Parker (1992) in turn found that the degree of sexual size dimorphism among spider families is correlated with the higher risk of predation suffered by males when compared to females. The importance of mortality risks and other host factors for parasitoid development is still often ignored despite Salt (1941) over half a century ago stating: "It is evident that, far from being a purely passive victim, obliterated without trace, the host is often able to impress its mark, and a very real mark at that, on the insect parasitoid that destroys it." Our results reaffirm Salt's observation by underscoring the importance of host feeding ecology when interpreting the fitness value of different developmental strategies. Future studies will undoubtedly shed light on other features of host biology affecting the life-history evolution of parasitoids and other third trophic level organisms.

\section{ACKNOWLEDGMENTS}

The authors wish to thank Joep Burger, Rieta Gols, Mark Jervis, and Marcel Visser for their comments on an early draft of the manuscript, and Jena Johnson and Kristy Kadash for assistance in maintenance of insect cultures. The work was funded by Hatch project 3929, NIH grant R01A132617, and NSF grant IBN-9514231 to M. R. Strand.

\section{Literature Cited}

Abrams, P. A., AND L. Rowe. 1996. The effects of predation on the age and maturity of prey. Evolution 50:1052-1061.

Ademo, S. A. 1997. How parasites alter the behavior of their insect hosts. Pages 231-245 in N. E. Beckage, editor. Parasites and pathogens: effects on host hormones and behavior. Chapman and Hall, New York, New York, USA.

Allen, G. R., and M. A. Keller. 1991. Urbana lugens (Lepidoptera: Noctuidae) and its parasitoids (Hymenoptera: Braconidae): temperature, host size and development. Environmental Entomology 20:458-469.

Allen, W. M. 1958. The biology of Apanteles medicanigis Meusebeck (Hymenoptera: Braconidae). Hilgardia 27:515541.

Askew, R. R. 1975. The organisation of chalcid-dominated parasitoid commmunities centred upon endophytic hosts. Pages $130-153$ in P. W. Price, editor. Evolutionary strategies of parasitic insects and mites. Plenum Press, New York, New York, USA.

Askew, R. R., and M. R. Shaw. 1986. Parasitoid communities: their size, structure and development. Pages 225-264 in J. K. Waage and D. Greathead, editors. Insect parasitoids. Academic Press, London, UK.

Beckage, N. E., and T. J. Templeton. 1985. Temporal synchronization of emergence of Hyposoter exiguae and $H$. fugitivus (Hymenoptera: Ichnuemonidae) with apolysis preceding larval molting in Manduca sexta (Lepidoptera: Sphingidae). Annals of the Entomological Society of America 78:775-782.

Benry, B., and R. F. Denno. 1997. The slow growth-high mortality hypothesis: a test using the cabbage butterfly. Ecology 78:987-999.

Blackburn, T. M. 1991. A comparative examination of life- span and fecundity in parasitoid Hymenoptera. Journal of Animal Ecology 60:151-164.

Bolling, J. C., and H. N. Pitre. 1970. Life history of Apanteles marginiventris with descriptions of immature stages. Journal of the Kansas Entomological Society 4:465-470.

Brodeur, J. 2000. Host specificity and trophic relationships of hyperparasitoids. Pages 163-183 in M. E. Hochberg and A. R. Ives, editors. Parasitoid population biology. Princeton University Press, Princeton, New Jersey, USA.

Brodeur, J., and J. N. McNeil. 1994. Life history of the aphid hyperparasitoid Asaphes vulgaris Walker (Pteromalidae): possible consequences on the efficacy of the primary parasitoid Aphidius nigripes Ashmead (Aphidiidae). Canadian Entomologist 126:1493-1497.

Brooks, W. M. 1993. Hosts-parasitoid-pathogen interactions. Pages 231-272 in N. E. Beckage, S. N. Thompson, and B. A. Federici, editors. Parasites and pathogens of insects. Academic Press, New York, New york, USA.

Calder, W. A., III. 1984. Size, function and life-history. Harvard University Press, Cambridge, Massachusetts, USA.

Campbell, B. C., and S. S. Duffey. 1979. Effect of density and instar of Heliothis zea on parasitization by Hyposoter exiguae. Environmental Entomology 8:127-130.

Charlesworth, B. 1980. Evolution in age-structured populations. Cambridge University Press, Cambridge, UK.

Clancy, K. M., and P. W. Price. 1987. Rapid herbivore growth enhances enemy attack: sublethal plant defenses remain a paradox. Ecology 68:736-738.

Cole, L. C. 1954. The population consequences of life history phenomena. Quarterly Review of Biology 29:103-137.

Cornell, H. V. 1990. Survivorship, life history, and concealment: a comparison of leaf miners and gall formers. American Naturalist 136:581-597.

Craig, T. P., J. K. Itami, and P. W. Price. 1990. The window of vulnerability of a shoot galling sawfly to attack by a parasitoid. Ecology 71:1471-1482.

Croft, P., and M. J. W. Copland. 1995. The effect of host instar on the size and sex ratio of the endoparasitoid Dacnusa sibrica. Entomologia Experimentalis et Applicata 74: 121-124.

Curio, E. 1989. Is avian mortality preprogrammed? Trends in Ecology and Evolution 4:81-82.

Cusson, M., C. Lucarotti, D. Stoltz, P. Krell, and D. Doucet. 1998. A polydnavirus from the spruce budworm parasitoid, Tranosema rostrale (Ichneumonidae). Journal of Invertebrate Pathology 72:50-56.

Felsenstein, J. 1985. Phylogenies and the comparative method. American Naturalist 125:1-15.

Ferguson, K. I., and P. Stiling. 1996. Non-additive effects of multiple natural enemies on aphid populations. Oecologia 108:375-379.

Gauld, I. D. 1988. Evolutionary patterns of host utilization by ichneumonoid parasitoids (Hymenoptera: Ichneumonidae and Braconidae). Biological Journal of the Linnean Society 57:137-162.

Gauld, I. D., and B. Bolton. 1988. The Hymenoptera. Oxford University Press, Oxford, UK.

Grossmuller, D. W., and R. C. Lederhouse. 1985. Oviposition site selection: an aid to rapid growth and development in the tiger swallowtail butterfly, Papilio glaucus. Oecologia 66:68-073.

Gunasena, G. H., S. B. Vinson, and H. J. Williams. 1989. Interrelationships between growth of Heliothis virescens (Lepidoptera: Noctuidae) and that of its parasitoid, Campoletis sonorensis (Hymenoptera: Ichneumonidae). Annals of the Entomological Society of America 82:187-191.

Harvey, J. A. 1995. The nutritional ecology of a host-parasitoid interaction. Dissertation. University of Liverpool, Liverpool, UK.

Harvey, J. A., I. F. Harvey, and D. J. Thompson. 1994. Flex- 
ible larval growth allows use of a range of host sizes by a parasitoid wasp. Ecology 75:1420-1428.

Harvey, J. A., M. A. Jervis, R. Gols, N. Jiang, and L. E. M. Vet. 1999. Development of the parasitoid, Cotesia rubecula (Hymenoptera: Braconidae) in Pieris rapae and Pieris brassicae (Lepidoptera: Pieridae) evidence for host regulation. Journal of Insect Physiology 45:173-182.

Harvey, J. A., K. Kadash, and M. R. Strand. 2000. Differences in larval feeding behavior correlate with altered developmental strategies in two parasitic wasps: implications for the size-fitness hypothesis. Oikos 88:621-629.

Harvey, J. A., and D. J. Thompson. 1995. Developmental interactions between the solitary endoparasitoid, Venturia canescens (Hymenoptera: Ichneumonidae) and two of its hosts, Plodia interpunctella and Corcyra cephalonica (Lepidoptera: Pyralidae). European Journal of Entomology 92: 427-435.

Harvey, J. A., and L. E. M. Vet. 1997. Venturia canescens parasitizing Galleria mellonella and Anagasta kuehniella: differing suitability of two hosts with highly variable growth potential. Entomologia Experimentalis et Applicata 84:93-100.

Harvey, P. H., and Pagel, M. D. 1991. The comparative method. Oxford University Press, Oxford, UK.

Hawkins, B. A. 1988. Do galls protect endophytic herbivores from parasitoids? A comparison of galling and non-galling Diptera. Ecological Entomology 13:473-477.

Hawkins, B. A., and J. H. Lawton. 1990. Species richness for parasitoids of British phytophagous insects. Nature 326: 788-790.

Hebert, C., and C. Cloutier. 1990. Host instar as a determinant of preference and suitability for two parasitoids attacking late instars of the spruce budworm (Lepidoptera: Tortricidae). Annals of the Entomological Society of America 83:734-741.

Hegazi, E. M., A. Schopf, E. Fuhrer, and S. H. Fouad. 1988. Developmental synchrony between Spodoptera littoralis (Boisd.) and its parasite Microplitis rufiventris Kok. Journal of Insect Physiology 34:773-778.

Heimpel, G. E., J. A. Rosenheim, and M. Mangel. 1997. Predation on adult iAphytis parasitoids in the field. Oecologia 110:346-352.

Hirshfield, M. F., and D. W. Tinkle. 1975. Natural selection and the evolution of reproductive effort. Proceedings of the National Academy of Sciences USA 72:2227-2231.

Johnson, T. M., and F. Gould. 1992. Interaction of genetically engineered host plant resistance and natural enemies of Heliothis virescens (Lepidoptera: Noctuidae) in tobacco. Environmental Entomology 21:586-597.

Jones, R. L., and W. J. Lewis. 1971. Physiology of the hostparasite relationship between Heliothis zea and Microplitis croceipes. Journal of Insect Physiology 17:921-927.

Jowyk, E. A., and Z. Smilowitz. 1978. A comparison of growth and development rates of the parasite Hyposoter exiguae reared from two instars of its host, Trichoplusia ni. Annals of the Entomological Society of America 71: 467-472.

King, B. H. 1989. Host-size dependent sex ratios among parasitoid wasps: does host size matter? Oecologia 78:420426.

King, E. G., and G. G. Hartley. 1985. Heliothis virescens. Pages 323-328 in P. Singh and R. F. Moore, editors. The handbook of insect rearing. Elsevier, Amsterdam, The Netherlands.

Leather, S. R. 1985. Oviposition preferences in relation to larval growth rates and survival in the pine beauty moth, Pannolis flammea. Ecological Entomology 10:213-217.

Lessells, C. M. 1991. The evolution of life-histories. Pages 32-68 in J. R. Krebs and N. R. Davies, editors. Behavioural ecology: an evolutionary approach. Blackwell Scientific Publications, Oxford, UK.

Lewis, W. J. 1970. Study of species and instars of larval Heliothis parasitized by Microplitis croceipes. Journal of Economic Entomology 63:363-365.

Lindgren, P. D., R. J. Guerra, J. W. Nickelson, and C. W. White. 1970. Hosts and host-age preference of Campoletis perdistinctus. Journal of Economic Entomology 63:519522.

Liu, S. S. 1985. Development, adult size, and fecundity of Aphidius sonchi reared on two instars of its aphid host, Hyperomyzus lacticae. Entomologia Experimentalis et Applicata 37:41-48.

Mackauer, M., and R. Sequeira. 1993. Patterns of development in insect parasites. Pages 1-23 in N. E. Beckage, S. N. Thompson, and B. A. Federici, editors. Parasites and pathogens of insects. Academic Press, New York, New York, USA.

Mackauer, M., R. Sequeira, and M. Otto. 1997. Growth and development in parasitoid wasps: adaptation to variable host resources. Pages 191-203 in K. Dettner, G. Bauer, and W. Volkl, editors. Vertical food web interactions: evolutionary patterns and driving forces.

Martin, T. E. 1995. Avian life history evolution in relation to nest sites, nest predation, and food. Ecological Monographs 65:101-127.

Moran, N., and W. D. Hamilton. 1980. Low nutritive value as a defense against herbivores. Journal of Theoretical Biology 86:247-254.

Patel, N., and M. Habib. 1987. Biological studies on Campoletis flavicinata (Ashmead, 1890) (Hym, Ichneumonidae), an endoparasite of the fall armyworm, Spodoptera frugiperda (Abbot and Smith 1797) (Lep, Noctuidae). Journal of Applied Entomology 104:28-35.

Pennachio, F., S. B. Vinson, E. Tremblay, and T. Tanaka. 1994. Biochemical and developmental alterations of Heliothis virescens (F.) (Lepidoptera, Noctuidae) larvae induced by the endophagous parasitoid, Cardiochiles nigriceps Viereck (Hymenoptera, Braconidae). Archives of Insect Biochemistry and Physiology 26:211-233.

Pettit, F. L., and D. O. Wietlisbach. 1993. Effects of host instar and size on parasitization efficiency and life history parameters of Opius dissitus. Entomologia Experimentalis et Applicata 66:227-236.

Powell, J. E., and G. W. Elzen. 1989. Biological and host relationships of Microplitis croceipes. Southwestern Entomologist 12:11-15.

Price, P. W. 1973. Reproductive strategies in parasitoid wasps. American Naturalist 107:684-693.

Price, P. W. 1974. Strategies for egg production. Evolution 28:76-84.

Price, P. W., C. E. Bouton, P. Gross, B. A. McPheron, J. N. Thompson, and A. E. Weis. 1980. Interactions among three trophic levels: influence of the plant on interactions between insect herbivores and natural enemies. Annual Review of Ecology and Systematics 11:41-65.

Quicke, D. L. J. 1997. Parasitic wasps. Chapman and Hall, London, UK.

Rees, N. E., and J. A. Onsager. 1982. Influence of predators on the efficiency of Blaesoxipha spp. parasites of the migratory grasshopper. Environmental Entomology 11:426428.

Rosenheim, J. A. 1998. Higher-order predators and the regulation of insect herbivore populations. Annual Review of Entomology 43:421-447.

Rosenheim, J. A., H. K. Kaya, L. E. Ehler, J. J. Marois, and B. A. Jaffee. 1995. Intraguild predation among biological control agents: theory and evidence. Biological Control 5: 303-335. 
Salt, G. 1941. The effects of hosts upon their insect parasites. Biological Reviews 16:239-264.

Schaffer, W. M. 1974. Selection for optimal life histories: the effects of age structure. Ecology 5:291-303.

Sequeira, R., and M. Mackauer. 1992a. Nutritional ecology of an insect host-parasitoid association: the pea aphidAphidius ervi system. Ecology 73:183-189.

Sequeira, R., and M. Mackauer. 1992b. Covariance of adult size and development time in the parasitoid wasp Aphidius ervi in relation to the size of its host, Acyrthosiphon pisum. Evolutionary Ecology 6:34-44.

Sequeira, R., and M. Mackauer. 1993. The nutritional ecology of a parasitoid wasp, Ephedrus californicus Baker (Hymenoptera: Aphidiidae). Canadian Entomologist 125:423430 .

Shaw, M. R. 1994. Parasitoid host ranges. Pages 111-144 in B. A. Hawkins and W. Sheehan, editors. Parasitoid community ecology. Oxford University Press, Oxford, UK.

Smith, H. A., J. L. Capinera, J. E. Pena, and B. Linboterhaar. 1994. Parasitism of pickleworm and meloworm (Lepidoptera, Pyralidae) by Cardiochiles-diaphaniae (Hymenoptera, Braconidae). Environmental Entomology 23:1283-1293.

Stearns, S. C. 1989. Trade-offs in life-history evolution. Functional Ecology 3:259-268.

Stiling, P., and A. M. Rossi. 1994. The window of paraistoid vulnerability to hyperparasitism: template for parasitoid complex structure. Pages 228-244 in B. A. Hawkins and W. Sheehan, editors. Parasitoid community ecology. Oxford University Press, Oxford, UK.

Strand, M. R. 1990. Characterization of larval development in Pseudoplusia includens (Lepidoptera: Noctuidae). Annals of the Entomological Society of America 83:538-544.

Strand, M. R. 2000. Developmental traits and life-history evolution in parasitoids. Pages 139-162 in M. E. Hochberg and A. R. Ives, editors. Parasitoid population biology. Princeton University Press, Princeton, New Jersey, USA.

Strand, M. R., J. A. Johnson, and J. R. Culin. 1988. Developmental interactions between the parasitoid Microplitis demolitor (Hymenoptera: Braconidae) and its host Heliothis virescens (Lepidoptera: Noctuidae). Annals of the Entomological Society of America 81:822-830.

Tanaka, T., Y. Sato, and T. Hidaka. 1984. Developmental interactions between Leucania separata (Lepidoptera: Noctuidae) and its braconid parasitoid, Microplitis mediator (Hymenoptera: Braconidae). Journal of Economic Entomology 77:91-97.

Visser, M. E. 1994. The importance of being large: the relationship between size and fitness in females of the parasitoid Aphaereta minuta (Hymenoptera: Braconidae). Journal of Animal Ecology 63:963-978.

Vollrath, F., and G. A. Parker. 1992. Sexual dimorphism and distorted sex ratios in spiders. Nature 360:156-158.

Waage, J. K., and H. C. J. Godfray. 1985. Reproductive strategies and population ecology of insect parasitoids. Pages 449-470 in R. M. Sibly and R. H. Smith, editors. Behavioural ecology (British Ecological Society Symposium 25). Blackwell Scientific Publications, Oxford, UK.

Wani, M., K. Iwabuchi, and J. Mitsuhashi. 1994. Developmental responses of Galleria mellonella (Lepidoptera: Pyralidae) larvae to parasitism by a braconid parasitoid, Apanteles galleriae (Hymenoptera: Braconidae). Applied Entomology and Zoology 29: 193-201.

Whitfield, J. B. 1998. Phylogeny and evolution of host-parasitoid interactions in Hymenoptera. Annual Review of Entomology 43:129-151.

Williams, I. 1999. Slow-growth, high mortality-a general hypothesis, or is it? Ecological Entomology 24:490-495. 